\title{
CRÓNICA DE JURISPRUDENCIA DEL TRIBUNAL EUROPEO DE DERECHOS HUMANOS, SEPTIEMBRE-DICIEMBRE 2017
}

\author{
MARTA CABRERA MARTÍN ${ }^{1}$ \\ Tribunal Europeo de Derechos Humanos \\ Marta.Cabrera.Martin@echr.coe.int
}

Cómo citar/Citation

Cabrera Martín, M. (2018).

Crónica de jurisprudencia del Tribunal Europeo de Derechos Humanos,

septiembre-diciembre 2017

Revista de Derecho Comunitario Europeo, 59, 413-435. doi: https://doi.org/10.18042/cepc/rdce.59.11

\section{SUMARIO}

I. INTRODUCCIÓN. II. PRINCIPALES SENTENCIAS Y DECISIONES DEL TEDH: 1. Derecho a la vida (artículo 2 del CEDH). 2. Derecho a no ser sometido a tortura ni a penas o tratos inhumanos o degradantes (artículo 3 del CEDH). 3. Derecho a un proceso equitativo (artículo 6 del CEDH). 4. Derecho al respeto a la vida privada y familiar (artículo 8 del CEDH). 5. Libertad de pensamiento, conciencia y religión (artículo 9 del CEDH). III. REFERENCIAS AL DERECHO DE LA UE EN LA JURISPRUDENCIA DEL TEDH. IV. ESPAÑA Y EL TRIBUNAL EUROPEO DE DERECHOS HUMANOS.

1 Letrada de apoyo del Tribunal Europeo de Derechos Humanos. 


\section{INTRODUCCIÓN}

La presente crónica tiene por objeto servir de referencia sobre la prolífica actividad jurisprudencial del Tribunal Europeo de Derechos Humanos (en adelante, TEDH o el Tribunal) durante el período comprendido entre los meses de septiembre y diciembre de 2017.

En primer lugar se realizará un análisis de las sentencias y decisiones más relevantes por su impacto en el desarrollo del contenido, naturaleza y ámbito de aplicación de los derechos contenidos en el Convenio Europeo de Derechos Humanos (en adelante, CEDH o el Convenio). Dicha jurisprudencia ha sido sistematizada siguiendo como patrón inicial el orden de los artículos del Convenio.

El siguiente apartado está destinado a comentar aquellos pronunciamientos en los que el Tribunal ha analizado instrumentos legales y jurisprudencia de la Unión Europea (en adelante, UE) como etapa previa para fundamentar algunos de sus fallos.

Finalmente, también se ha considerado oportuno realizar un somero resumen de las sentencias y decisiones más relevantes del Tribunal dictadas en relación con España a lo largo de este cuatrimestre.

\section{PRINCIPALES SENTENCIAS Y DECISIONES DEL TEDH}

\section{DERECHO A LA VIDA (ARTÍCULO 2 DEL CEDH)}

En primer lugar nos centraremos en la sentencia recaída en el caso Lopes de Sousa Fernandes c. Portugal ${ }^{2}$, en virtud de la cual la Gran Sala del Tribunal analizó la responsabilidad de un Estado por la muerte de un paciente en un hospital público.

El 27 de noviembre de 1997 el marido de la demandante, el Sr. Fernandes, fue operado de una polipectomía nasal. Dos días después de la operación el Sr. Fernandes acudió a urgencias ya que sufría unos fuertes dolores de cabeza. El neurólogo que lo examinó consideró que el Sr. Fernandes sufría un problema de índole psicológico y le prescribió unos tranquilizantes.

A la mañana siguiente se le hizo una punción lumbar en la que se descubrió que el Sr. Fernandes padecía una meningitis bacteriana. Además, el 30 de noviembre se le hizo un escáner cerebral en el que se descubrió que el deman-

2 Lopes de Sousa Fernandes v. Portugal [GC], no. 56080/13. 
dante tenía un edema cerebral. El 13 de diciembre, una vez los médicos consideraron que su situación de salud era estable, el Sr. Fernandes fue dado de alta.

El 18 de diciembre el Sr. Fernandes acudió nuevamente a urgencias hospitalarias aduciendo que sufría dolores de cabeza, vértigo y diarrea. Tras pasar varios días en el hospital, el 23 de diciembre los médicos le dieron nuevamente el alta al paciente y le prescribieron un tratamiento para la diarrea, además de otro tipo de medicación. El Sr. Fernandes volvió a acudir al hospital el 9 de enero de 1998, donde fue atendido por un médico que consideró que no debía ingresarle.

El 25 de enero se realizó una prueba que reveló que tenía una infección bacteriana. Los médicos le prescribieron un tratamiento con antibióticos y le dieron el alta. No obstante, la situación del Sr. Fernandes no mejoró. Tal es así que el 17 de febrero el Sr. Fernandes acudió nuevamente al hospital ya que sufría de diarrea crónica y anemia microcrítica. Los médicos realizaron numerosas pruebas tras las cuales no se llegó a un diagnóstico claro.

Finalmente, el 7 de marzo a las 13:00 horas el Sr. Fernandes fue examinado nuevamente por un médico $y$, posteriormente, por un cirujano, quien decidió operarle de urgencia tras comprobar que sufría de una peritonitis que se le había extendido. La operación se inició a las 16:00 horas, si bien tuvo que suspenderse para poder hacerle una transfusión de sangre. Finalmente fue operado a las 20:00 horas. El Sr. Fernandes falleció al día siguiente a las 02:55 horas. De conformidad con el certificado de defunción realizado por el hospital, la causa de fallecimiento del Sr. Fernandes fue una septicemia derivada de una peritonitis y una perforación de víscera.

Tras la muerte de su marido, la demandante remitió una carta al hospital informando de los hechos acaecidos, en virtud de la cual el inspector general de Salud ordenó que se realizara una investigación interna. Según informes realizados en los años 2002 y 2005, el Sr. Fernandes habría sido tratado de manera correcta, razón por la cual el caso fue archivado. Sin embargo, un nuevo informe realizado por el doctor J. V. consideraba que el tratamiento aplicado al Sr. Fernandez no había sido ni adecuado ni apropiado.

Cabe señalar que la demanda interpuesta por la demandante ante la Asociación de Médicos así como la denuncia por homicidio ante el juez de Instrucción de Oporto también resultaron infructuosas. Finalmente, la demandante interpuso una demanda por reclamación de daños contra el Estado, la cual fue desestimada al no haber quedado acreditado que la muerte de su marido fuera debida a un tratamiento incorrecto.

La demandante acudió ante el TEDH invocando los arts. 2, 6.1 y 13 del Convenio. En lo que respecta a la violación del art. 2, la demandante argumentó que su marido había muerto como consecuencia directa de una infección contraída en el hospital, lo cual supuso una violación de la vertiente 
sustantiva del referido artículo. También alegó que se había producido una violación de la vertiente procesal del art. 2 debido a la incapacidad de las autoridades sanitarias de determinar las causas de deterioro de la salud de su marido.

El 15 de diciembre de 2015 la Sala de la Sección Cuarta declaró que se había producido una violación tanto del aspecto sustantivo como del procesal del art. $2^{3}$. No obstante, dicha sentencia fue recurrida ante la Gran Sala, la cual el 19 de diciembre de 2017 dictaminó que solo se había producido una violación del aspecto procesal del art. 2 .

La importancia de la presente sentencia radica en el hecho de que realiza una revisión y, además, clarifica la jurisprudencia del TEDH sobre el alcance de las obligaciones positivas de los Estados en casos de muertes derivadas de una presunta negligencia médica. Así, la sentencia confirma que la obligación es de «regulación» y que solo en casos excepcionales se podrá considerar que el Estado es responsable por actos u omisiones realizadas por proveedores de salud ${ }^{4}$. En particular, la Gran Sala confirmó que, en casos donde un Estado ha diseñado e implementado un marco regulatorio con una normativa adecuada que garantice altos estándares profesionales, el error cometido por un profesional de la salud no es suficiente para que se considere que el Estado ha incumplido con las obligaciones positivas derivadas de la vertiente sustantiva del artículo5.

Así, solo en casos muy excepcionales se podría atribuir responsabilidad directa al Estado por la violación de la vertiente sustantiva del art. $2^{6}$. La Gran Sala entró a analizar si el presente caso se enmarcaba en alguna excepción. Para ello el Tribunal ha establecido un test estricto que requiere la presencia de los siguientes factores cumulativos: (i) que los actos u omisiones del proveedor de salud vayan más allá de un simple error o negligencia médica en la medida en que haya violado sus obligaciones profesionales y haya negado a un paciente un tratamiento médico a pesar de ser plenamente consciente que la vida de esa persona pudiera estar en riesgo si no se le proporciona dicho tratamiento; (ii) que tal anomalía sea objetiva y genuinamente identificada como un problema sistémico o estructural; (iii) que exista un nexo de conexión entre tal anomalía y el daño causado, y (iv) que la anomalía sea el resultado de un fallo del

\footnotetext{
Lopes de Sousa Fernandes v. Portugal, no. 56080/13

Ibid., párr. 186.

Ibid., párr. 165. Véase también, Powell v. the United Kingdom (dec.), no. 45305/99 y Sevim Güngör v. Turkey (dec.), no. 75173/01.

6 Véanse también Mehmet Şentürk and Bekir Şentürk v. Turkey, no. 13423/09 y Asiye Genç v. Turkey, no. 24109/07 y Aydoğdu v. Turkey, no. 40448/06.
} 
Estado a la hora de cumplir con su obligación de establecer un marco regulatorio adecuado ${ }^{7}$.

El TEDH aplicó dicho test al presente caso y concluyó por tanto que no se había producido una violación de la vertiente sustantiva del art. 2 del Convenio.

Por otro lado, el TEDH confirmó su jurisprudencia respecto a las obligaciones que dimanan de la vertiente procesal del citado artículo. La Gran Sala reiteró que un Estado tiene la obligación de implementar un sistema judicial independiente que permita determinar la causa de muerte de un paciente y depurar responsabilidades, tanto en el sector público como en el privado ${ }^{8}$.

A este respecto, el TEDH consideró que en el presente caso existieron «razones de peso» (arguable grounds) para sospechar que el marido de la demandante podría haber muerto por causa de una negligencia médica y, por tanto, el Estado tenía la obligación de respetar las obligaciones que dimanan de la vertiente procesal del art. $2^{9}$. Toda vez que existía un recurso en el ámbito disciplinario, civil y penal, el sistema cumplía «en teoría» con dichas obligaciones ${ }^{10}$. Sin embargo, la Gran Sala consideró que ninguno de los procedimientos disciplinarios, penales y civiles iniciados por la demandante fue efectivo, por lo cual declaró la violación del art. 2 en su vertiente procesal.

\section{DERECHO A NO SER SOMETIDO A TORTURA NI A PENAS O TRATOS INHUMANOS O DEGRADANTES (ARTÍCULO 3 DEL CEDH)}

En este apartado debe destacarse la sentencia recaída en el caso S.F. y otros c. Bulgaria ${ }^{11}$. El 14 de agosto de 2015 los demandantes, huyendo de Irak, consiguen cruzar la frontera turco-búlgara ilegalmente junto a otras cuatro familias. Los demandantes tenían en aquel momento dieciséis, once y un año y medio. El 17 de agosto de 2015 los demandantes viajaban en un coche hacia la frontera búlgaro-serbia. Cuando estaban a pocos metros de la frontera, dos oficiales búlgaros los interceptaron y detuvieron.

Los demandante fueron internados en un centro de inmigrantes por un período de entre 32 y 41 horas (el tiempo total ha sido una cuestión controver-

\footnotetext{
Lopes de Sousa Fernandes v. Portugal [GC], supra nota 3, párrs. 194 a 196.

Ibid., párr. 214.

Ibid., párr. 222.

Ibid., párr. 224.

11 S.F. and Others v. Bulgaria, no. 8138/16. Cabe señalar que dicha sentencia no ha alcanzado, al momento de redacción de la presente crónica, firmeza, de conformidad con lo estipulado en el art. 44.2 del Convenio.
} 
tida por las partes). En particular, los demandantes fueron encerrados en una celda con varias literas con sábanas y colchones desgastados, llena de basura y con cartón húmedo en el suelo. Tenían acceso limitado al baño, lo cual les obligó a orinar en la misma celda en la que estuvieron encerrados. Presuntamente las autoridades no les dieron ningún tipo de bebida o comida hasta pasadas veinticuatro horas. Además, la madre del demandante más pequeño no tuvo acceso a una botella de leche hasta diecinueve horas después de haber sido puestos bajo custodia.

Para analizar la presente situación el Tribunal tomó como referencia su reciente jurisprudencia relativa a menores encerrados en centros de inmigrantes $^{12}$, destacando que la detención de menores migrantes (acompañados o no) plantea cuestiones relativas a la extrema vulnerabilidad de estos ${ }^{13}$. El Tribunal declaró expresamente que esta extrema vulnerabilidad de los menores es un «factor decisivo" y "prevalece» sobre su estatus administrativo $^{14}$. Con base en lo estipulado en el art. 22.1 de la Convención sobre los Derechos del Niño, el Tribunal recalcó la obligación de todos los Estados de otorgar una protección y asistencia humanitaria apropiada a los menores solicitantes de asilo.

El Tribunal aprovechó la presente oportunidad para realizar un resumen conciso sobre la jurisprudencia dictada hasta la fecha sobre menores y sus condiciones de detención en centros de inmigrantes.

Tras realizar el anterior análisis, el TEDH consideró que el tiempo en que los demandantes estuvieron detenidos (independientemente de cuál fuera la versión correcta en cuanto al tiempo total de la detención) era un período mucho más corto que el que había sido analizado en casos anteriores. No obstante, las condiciones en las que estuvieron detenidos los menores eran «considerablemente peores» que aquellas analizadas en otros $\operatorname{casos}^{15}$.

Según el Tribunal, el hecho de haber sometido a los demandantes a dichas condiciones, incluso en lo que se puede considerar un corto período de tiempo, supuso un trato inhumano y degradante del cual el Estado búlgaro era responsable ${ }^{16}$. El Tribunal reconoció las recientes dificultades que deben afrontar los Estados fronterizos del Consejo de Europa. No obstante, el TEDH recordó el carácter absoluto del art. 3, recalcando que incluso un influjo masivo de

12 En particular, Khlaifia and Others v. Italy [GC], no. 16483/12, párrs. 158 a 167.

13 Ver, inter alia, Abdullahi Elmi and Aweys Abubakar v. Malta, nos. 25794/13 y 28151/13, párr. 103.

14 S.F. and Others v. Bulgaria, supra nota 11, párr. 79.

15 Ibid., párr. 84.

16 Ibid., párrs. 84 a 90. 
inmigrantes no exonera a los Estados parte de sus obligaciones dimanantes del citado art. 3, el cual requiere, entre otros, que las personas privadas de libertad tengan garantizado el respeto a su dignidad humana ${ }^{17}$. Por todo lo anterior el Tribunal concluyó que Bulgaria violó el art. 3 del Convenio ${ }^{18}$.

\section{DERECHO A UN PROCESO EQUITATIVO (ARTÍCULO 6 DEL CEDH)}

El 23 de noviembre de 2017 el TEDH emitió la interesante sentencia relativa al caso Haarde c. Islandia ${ }^{19}$, en el cual se analizó la compatibilidad del art. 6 con un juicio político (impeachment) seguido contra el anterior primer ministro de Islandia.

En particular, el demandante había sido primer ministro de Islandia entre los años 2006 y 2009. El demandante fue acusado en un juicio político de seis cargos relacionados con el colapso del sistema financiero islandés en octubre de 2008. Dicha acusación había sido precedida de la creación de una comisión de investigación creada al efecto para investigar las causas del colapso, de un comité parlamentario de revisión y de la elección de un fiscal parlamentario. Finalmente, el demandante fue únicamente "condenado" por un cargo (negligencia grave por no convocar reuniones ministeriales sobre asuntos de gran relevancia, tal y como así lo establecían el art. 17 de la Constitución y el art. 8c de la Ley de Responsabilidad Ministerial).

El demandante acudió ante el TEDH aduciendo que dicho proceso, incluyendo la fase de investigación y la fase de procesamiento y condena, había sido arbitrario y meramente político. Acusó a los órganos de investigación de haber realizado una investigación fallida en detrimento de la equidad del procedimiento y que el órgano juzgador no había sido imparcial. El Tribunal, no obstante, consideró que no se produjo ninguna violación.

El interés de la presente sentencia radica en el contexto y manera en la cual el TEDH analizó las quejas del demandante desde la perspectiva del art. 6 del Convenio. El Tribunal analizó el procedimiento sin entrar a valorar la cuestión de si dicho procedimiento versaba sobre «la determinación de un cargo/infracción penal» contra él. Cabe señalar, eso sí, que lo anterior no fue controvertido por el Gobierno.

\footnotetext{
Ibid., párr. 92.

Ibid., párr. 93.

19 Haarde v. Iceland, no. 66847/12. Cabe señalar que dicha sentencia no ha alcanzado, al momento de redacción de la presente crónica, firmeza, de conformidad con lo estipulado en el art. 44.2 del Convenio.
} 
El TEDH observó que la recolección de pruebas en la fase previa al juicio no había perjudicado los intereses de la defensa ${ }^{20}$. Asimismo, el Tribunal observó que muchos Estados han adoptado diferentes mecanismos para tratar la responsabilidad de los miembros de Gobierno por actos u omisiones cometidos en el ejercicio de sus funciones. Así, el Tribunal señaló que, si bien el marco constitucional, legal y procesal de esta materia buscaba el balance entre la responsabilidad política y la responsabilidad penal, podrían surgir situaciones en las que se cometieran abusos, los cuales deben ser evitados ${ }^{21}$.

El Tribunal también indicó que el hecho de que la decisión de procesar a un miembro del Gobierno fuera tomada por el Parlamento (y, por tanto, pudiera tener algún tinte político) no era en sí mismo suficiente para que se produjera una violación del art. 6: lo relevante en el presente caso fue si la decisión sobre la culpabilidad o inocencia del demandante fue adoptada por un tribunal con base en la prueba aportada en un procedimiento justo ${ }^{22}$.

Finalmente, el Tribunal analizó la queja del demandante relativa al hecho de que ocho de los jueces de la Court of Impeachment habían sido nombrados por el Parlamento, incluido el fiscal, lo cual hacía cuestionar la independencia e imparcialidad del mismo.

Para analizar la presente cuestión el Tribunal tuvo en cuenta el «carácter especial» de la Court of Impeachment, observando asimismo que, si bien podía presumirse la existencia de cierta «simpatía política» a la hora de seleccionar a los jueces, este factor por sí mismo no era suficiente para generar una duda legítima respecto a su independencia e imparcialidad ${ }^{23}$. Para el Tribunal fue crucial el hecho de que la legislación establecía una serie de garantías destinadas a asegurar su independencia e imparcialidad y que no hubo ningún elemento que indicara algún tipo de sesgo en la independencia de dicho tribunal $^{24}$. Por todo lo anterior, el Tribunal consideró, de manera unánime, que no hubo violación del art. 6 del Convenio.

\section{DERECHO AL RESPETO A LA VIDA PRIVADA Y FAMILIAR (ARTÍCULO 8 DEL CEDH)}

El 5 de septiembre de 2017 la Gran Sala emitió una importante y mediática sentencia relativa a la protección del derecho a la vida privada/correspondencia

\footnotetext{
20 Ibid., párr. 82.

21 Ibid., párr. 85.

22 Ibid., párrs. 86 y 86.

23 Ibid., párr. 105.

24 Ibid., párrs. 105 a 108.
} 
de los trabajadores en su lugar de trabajo: la sentencia recaída en el caso Bărbulescu v. Rumanía ${ }^{25}$.

El demandante trabajó como ingeniero de ventas en una empresa privada desde el 1 de agosto de 2004 hasta el 1 de agosto de 2007, día que fue despedido. El empleador había prohibido expresamente a sus empleados la realización de actividades personales en el lugar de trabajo, lo cual también incluía el uso por parte de los empleados de los recursos de la compañía para cuestiones personales. Dicha prohibición figuraba en un reglamento interno. Cabe señalar que el referido reglamento no incluía ninguna referencia a la posibilidad de que el empleador pudiera monitorizar las comunicaciones de sus empleados.

Entre los días 5 y 13 de julio de 2007 el empleador monitorizó todas las conversaciones del demandante realizadas mediante Yahoo Messenger, tanto a través de la cuenta que fue creada por instrucción del empleador para comunicarse con los clientes como a través de su cuenta personal.

El 13 de julio de 2007 el demandante fue convocado a una reunión en la que se le informó de lo sucedido y de que existían por tanto pruebas que demostraban que su actividad en internet era muy superior a la de sus compañeros y que además había utilizado las herramientas de la empresa para cuestiones personales. En dicha reunión no se le indicó que la monitorización de sus comunicaciones también incluía el acceso al contenido de las mismas. El demandante negó los hechos y explicó que había utilizado Yahoo Messenger por motivos de trabajo. El empleador entonces le adjunto un dosier de 45 páginas que contenía la transcripción de las conversaciones que había mantenido el demandante con su hermano y su prometida durante el período de monitorización. Las conversaciones eran de carácter personal, algunas de ellas de contenido muy íntimo.

El 1 de agosto de 2007 el demandante fue despedido. El demandante entonces inició un procedimiento laboral argumentando que el despido había sido nulo, toda vez que la monitorización de sus conversaciones había violado su derecho a la vida privada y correspondencia. A lo largo del procedimiento laboral fueron aportadas las transcripciones de las comunicaciones realizadas por el demandante, que además fueron utilizadas como prueba para acreditar que el demandante no había cumplido con el reglamento interno respecto al uso de las herramientas de trabajo.

Se debe señalar que este caso fue analizado en primer lugar por la Sala de la Sección cuarta del Tribunal, la cual inicialmente había declarado que no se había producido una violación del art. 8 del Convenio. La sentencia fue

25 Bărbulescu v. Romania [GC], no. 61496/08. 
recurrida ante la Gran Sala, que el 5 de septiembre de 2017 revocó la sentencia recaída en primera instancia y declaró que se había producido una violación del art. 8 del Convenio.

El presente caso dio la oportunidad al TEDH de analizar una serie de cuestiones interesantes relativas a los derechos y obligaciones de los empleados en el marco de las comunicaciones electrónicas en el lugar de trabajo. En primer lugar, la Gran Sala debía determinar si el art. 8 era de aplicación y si se podía considerar que el demandante tenía una expectativa razonable de privacidad. Así, si bien el demandante había sido informado de que no podía realizar actividades personales a través de herramientas del trabajo, lo cierto es que el demandante no había sido informado de que el contenido de sus conversaciones podía ser monitorizado, esto es, no había sido informado de la naturaleza y el alcance de la monitorización. Interesantemente, la Gran Sala del Tribunal decidió dejar la cuestión abierta en relación a la razonable expectativa de privacidad ya que, en todo caso, «las instrucciones de un empleador no pueden reducir la vida social privada en el lugar de trabajo a cero ${ }^{26}$. El Tribunal añadió que «el respecto a la vida privada y a la correspondencia continúa existiendo incluso en los casos en los que ésta deba ser restringida ${ }^{27}$.

Sentado lo anterior, la cuestión principal fue determinar si el Estado había cumplido con su obligación positiva de garantizar los derechos que dimanan del art. 8 en el lugar de trabajo. Se deben destacar varios aspectos relevantes.

En primer lugar, la Gran Sala señaló que, si bien en ciertos contextos la obligación positiva implicaba que el Estado implementara un marco legislativo, la Gran Sala consideró que los Estados parte debían disfrutar de un amplio «margen de apreciación» en relación con el marco legal relativo a las condiciones en las cuales un empleador puede regular las comunicaciones electrónicas, así como otro tipo de comunicaciones de naturaleza no profesional ${ }^{28}$. Sin embargo, el Tribunal destacó que este margen no otorgaba a los Estados una discreción ilimitada, toda vez que las autoridades tienen la obligación de verificar que la implementación por parte de un empleador de medidas de control de la correspondencia y otro tipo de comunicaciones debe ir acompañada de "garantías adecuadas y suficientes contra el uso abusivo», junto con garantías procesales contra actos arbitrarios, así como verificar que dichas medidas eran proporcionales ${ }^{29}$.

\footnotetext{
26 Ibid., párr. 80.

27 Ibid.

28 Ibid., párr. 119.

29 Ibid., párr. 121.
} 
Por otro lado, la Gran Sala vino a establecer cuáles son los criterios que deben ser analizados a la hora determinar si un Estado ha cumplido con sus obligaciones positivas en relación con la protección del derecho a la vida privada en el ámbito laboral:

(i) Se deberá analizar si el empleado ha sido notificado de la posibilidad de que el empleador monitorice su correspondencia u otras comunicaciones, así como la forma y naturaleza de dicho control. El empleado debe ser informado de manera previa.

(ii) Se deberá analizar el alcance de la monitorización así como el grado de intrusión en la vida privada del empleado. A este respecto, se debe hacer una distinción entre el control del flujo de comunicación y su contenido, si se han monitorizado todas sus comunicaciones o solo algunas, y se debe analizar si la monitorización fue limitada en el tiempo así como las personas que tuvieron acceso a los resultados.

(iii) Se deberá analizar si el empleador ha dado razones legítimas que justifiquen la monitorización de las comunicaciones y el acceso al contenido de las mismas, en cuyo caso la justificación deberá ser mucho mayor.

(iv) Se deberá analizar si habría sido posible implementar un sistema de monitorización menos intrusivo que el acceso directo al contenido de las comunicaciones.

(v) Se deberán analizar las consecuencias de la monitorización sobre el empleado, así como el uso dado por el empleador a los resultados obtenidos de la operación de monitoreo, y, en particular, si los resultados fueron utilizados para obtener el objetivo inicial de la medida ${ }^{30}$.

(vi) Por último, se deberá analizar si el empleado tuvo a su disposición suficientes herramientas que garantizaran, especialmente, que el empleador no pueda acceder al contenido de las comunicaciones salvo en los casos en los que haya informado previamente al empleado de tal posibilidad.

Así, si bien la Gran Sala consideró que los tribunales nacionales habían identificado de manera correcta el problema en cuestión, se había producido una violación del art. 8 toda vez que dichos tribunales no aplicaron los criterios mencionados anteriormente. Con todo, a pesar del «margen de apreciación» del que gozaba el Estado rumano, el Tribunal consideró que las autoridades nacionales erraron a la hora de realizar un «balance justo» entre los diferentes derechos analizados ${ }^{31}$.

$30 \quad$ Ibid., párr. 121.

31 Ibid., párr. 114. 


\section{LIBERTAD DE PENSAMIENTO, CONCIENCIA Y RELIGIÓN (ARTÍCULO 9 DEL CEDH)}

En el presente acápite debe ser destacado el caso Adyan y otros c. Arme$n i a^{32}$. Los demandantes, testigos de Jehová, hicieron uso de su derecho a la objeción de conciencia para no realizar el servicio militar. Asimismo, también se opusieron a la realización de un "servicio alternativo" que había sido introducido en el año 2004. Ante esta negativa, los demandantes fueron acusados por la vía penal por «evasión del servicio militar y de un servicio alternativo». A lo largo del procedimiento los demandantes argumentaron que el servicio alternativo no tenía una «naturaleza genuinamente civil», toda vez que el mismo estaba supervisado por autoridades militares, poseía una naturaleza punitiva y que su consciencia no les permitía trabajar directa o indirectamente para los militares.

Finalmente, los demandantes fueron condenados a más de dos años de prisión, de los cuales cumplieron entre 26 y 27 meses de pena, período tras el cual fueron puestos en libertad como beneficiarios de una amnistía general.

Los demandantes acudieron ante el TEDH invocando el art. 9 del Convenio. El Tribunal recordó su sentencia histórica relativa al caso Bayatyan c. Armenia $^{33}$ en la cual la Gran Sala analizó el ámbito de protección del citado art. 9 y su aplicabilidad a los objetores de conciencia ${ }^{34}$. Si bien la Gran Sala ya había reconocido que el art. 9 se aplicaba a los objetores de conciencia, en el presente caso se debía analizar una especificidad aún mayor, esto es, cuando el objetor de conciencia también rechaza el servicio alternativo, algo que no se había dado en el referido caso Bayatyan.

En primer lugar, el TEDH consideró que el art. 9 era también de aplicación a este tipo de objeción, toda vez que la misma era una manifestación de sus creencias religiosas ${ }^{35}$ y la condena a los demandantes había supuesto una injerencia en su derecho a manifestar su religión, tal y como así lo garantiza el art. 9 del Convenio ${ }^{36}$.

A la hora de analizar la necesidad de dicha injerencia, el Tribunal observó que el hecho de que Armenia hubiera implementado un servicio alternativo al servicio militar no se podía considerar suficiente como para concluir que las autoridades habían dado cumplimiento a las obligaciones dimanantes del

\footnotetext{
32 Adyan and Others v. Armenia, no. 75604/11.

33 Bayatyan v. Armenia [GC], no. 23459/03.

34 Ibid., párr. 110.

35 Adyan and Others v. Armenia, supra nota 32, párr. 54.

36 Ibid., párr. 60.
} 
art. $9^{37}$. A continuación, el Tribunal indicó que el derecho a la objeción de conciencia garantizado por el art. 9 del Convenio se convertiría en «ilusorio» si los Estados pudieran implementar un sistema alternativo en el cual no se pudiera ofrecer una alternativa real de naturaleza genuinamente civil diferente al servicio militar ${ }^{38}$.

Para ello, el TEDH analizó el servicio alternativo ofrecido a los demandantes y observó que, si bien el trabajo sería realizado en instituciones civiles (por ejemplo, orfanatos y hospitales) y era de naturaleza civil, lo cierto es que las autoridades militares participaban activamente en la supervisión de su trabajo ${ }^{39}$. El Tribunal también puso especial atención en el hecho de que las autoridades militares tenían el poder de ejercer influencia en el servicio y ordenar el traslado a otra institución o lugar de trabajo. Asimismo, algunos aspectos del servicio alternativo se regían por un Reglamento interno de las Fuerzas Armadas. A mayor abundamiento, los trabajadores tenían la obligación de llevar un uniforme, seguir órdenes y de permanecer en su lugar de trabajo salvo autorización.

En vista de lo anterior, el Tribunal concluyó que el servicio alternativo no estaba suficientemente separado jerárquica e institucionalmente del sistema militar ${ }^{40}$. En lo que respecta a la naturaleza punitiva o disuasoria del servicio alternativo, el Tribunal observó además que la duración del mismo (42 meses) era mucho más larga que la duración del servicio militar (24 meses). Según el Tribunal, una diferencia tan significativa tenía un efecto disuasorio que contenía elementos de carácter punitivo ${ }^{41}$.

Por todo lo anterior, el Tribunal concluyó que el Estado armenio violó el citado art. 9 del Convenio. Cabe señalar que la ley que regula el servicio alternativo fue modificada en el año 2013 e implementó un servicio alternativo de carácter puramente civil.

\section{REFERENCIAS AL DERECHO DE LA UE EN LA JURISPRUDENCIA DEL TEDH}

Tal y como veremos a continuación, el TEDH ha acudido en numerosas ocasiones a textos de la UE (derecho derivado, jurisprudencia, opiniones de

\footnotetext{
37 Ibid., párr. 67.

38 Ibid.

39 Adyan and Others v. Armenia, supra nota 32, párr. 69.

40 Ibid.

41 Adyan and Others v. Armenia, supra nota 32, párr. 70.
} 
grupos especializados, etc.) para analizar cuestiones de gran relevancia dentro del escenario europeo tan variante. Lo anterior sirve para ilustrar los innegables paralelismos existentes en la manera de interpretar los tratados de derechos humanos y observar cómo ambas jurisdicciones toman en consideración de manera creciente el enfoque de la otra en materia de protección de los derechos humanos.

Un primer ejemplo es Bărbulescu v. Rumanía ${ }^{42}$, el cual ya ha sido analizado en el apartado II.4 de la presente crónica y versa sobre los límites del derecho a la vida privada en el ámbito laboral.

Para abordar el presente caso la Gran Sala del TEDH acudió, entre otros instrumentos, a la Carta de los Derechos Fundamentales de la Unión Europea y, en específico, a los arts. 7 y 8 de la misma. Asimismo, el Tribunal también centro su análisis en la Directiva 95/46/CE, relativa a la protección de las personas físicas en lo que respecta al tratamiento de datos personales y a la libre circulación de estos datos. El Tribunal a continuación hizo referencia al Grupo de Trabajo sobre protección de datos, creado en virtud del art. 29 de la citada Directiva 95/46/CE. El TEDH destacó su Dictamen 8/2001 sobre el tratamiento de datos personales en el contexto laboral ${ }^{43}$, el cual resume los principios fundamentales de la protección de datos: finalidad, transparencia, legitimidad, proporcionalidad, exactitud, seguridad y conocimiento. El Tribunal destacó la observación realizada por el Grupo de Trabajo en cuanto a que el monitoreo de un empleado debe ser una «respuesta proporcional de un empleador a los riesgos a los que se enfrentan, teniendo en cuenta el legítimo derecho a la privacidad así como otros intereses de los trabajadores». Asimismo, el Tribunal hizo mención también a la jurisprudencia del TJUE que ha interpretado la citada Directiva 95/46/CE, y, en particular, a la sentencia recaída en el caso Österreichischer Rundfunk y otros ${ }^{44}$.

Por último, el TEDH hizo específica referencia al relativamente reciente Reglamento 2016/679, relativo a la protección de las personas físicas en lo que respecta al tratamiento de datos personales y a la libre circulación de estos datos y por el que se deroga la Directiva 95/46/CE ${ }^{45}$. Todo lo anterior sirvió como fundamento para la declaración de violación del art. 8 del Convenio.

42 Bărbulescu v. Romania [GC], supra nota 25.

43 Dictamen 8/2001 sobre el tratamiento de datos personales en el contexto laboral y resumen, de 13 de septiembre de 2001.

44 Sentencia del Tribunal de Justicia de 20 de mayo de 2003, Österreichischer Rundfunk y otros, C-465/00, C-138/01 y C-138/01, EU:C:2003:294.

45 Reglamento (UE) 2016/679 del Parlamento Europeo y del Consejo, de 27 de abril de 2016, relativo a la protección de las personas físicas en lo que respecta al tratamiento 
Otro caso que merece ser destacado es el caso Regner c. República Checa ${ }^{46}$, el cual versó sobre la compatibilidad de las garantías del art. 6 con la prohibición de acceso a determinada información clasificada como confidencial, la cual constituyó además la prueba esencial en el procedimiento judicial. En el presente caso la Agencia Nacional de Seguridad checa había decidido revocar la autorización de seguridad (security clearance) al demandante sobre la base de que constituía una amenaza para la seguridad nacional. Sin embargo, ni él ni su abogado tuvieron acceso a unos documentos clasificados como confidenciales.

Para analizar el presente caso, la Gran Sala del Tribunal acudió a dos sentencias específicas del TJUE. La primera de ellas fue la sentencia recaída en el caso $Z Z^{47}$, la cual versó sobre la interpretación del art. 30.2 de la Directiva 2004/38/CE, relativa al derecho de los ciudadanos de la Unión y de los miembros de sus familias a circular y residir libremente en el territorio de los Estados miembros ${ }^{48}$. En dicha sentencia el TJUE dirimía una disputa entre una persona con doble nacionalidad francesa y argelina y las autoridades migratorias de Reino Unido, que versaba sobre la decisión por parte de las autoridades de denegarle la entrada al país por razones de seguridad pública.

El Tribunal hizo especial referencia a lo declarado por el TJUE en cuanto a que en los casos excepcionales en que una autoridad nacional se opusiera a que se comunicara al interesado las razones que constituyesen el fundamento de una resolución adoptada en virtud del art. 27 de la Directiva 2004/38, invocando para ello motivos relacionados con la seguridad del Estado, «el juez competente del Estado miembro de que se trate habrá de tener a su disposición y deberá aplicar técnicas y normas de Derecho procesal que le permitan conciliar, por un lado, las legítimas consideraciones de seguridad del Estado en cuanto a la naturaleza y a las fuentes de la información tenida en cuenta para adoptar una resolución de ese tipo y, por otro, la necesidad de garantizar

de datos personales y a la libre circulación de estos datos y por el que se deroga la Directiva 95/46/CE (Reglamento general de protección de datos), DO L 119, de 4 de mayo de 2016, págs. 1 y ss.

46 Regner v. the Czech Republic [GC], no. 35289/11.

47 Sentencia del Tribunal de Justicia (Gran Sala) de 4 de junio de 2013, ZZ, C-300/11, EU:C:2013:363.

48 Directiva 2004/38/CE, relativa al derecho de los ciudadanos de la Unión y de los miembros de sus familias a circular y residir libremente en el territorio de los Estados miembros por la que se modifica el Reglamento (CEE) 1612/68 y se derogan las Directivas 64/221/CEE, 68/360/CEE, 72/194/CEE, 73/148/CEE, 75/34/CEE, 75/35/ CEE, 90/364/CEE, 90/365/CEE y 93/96/CEE, DO L 158, de 30 de abril de 2004, págs. $77 \mathrm{y}$ ss. 
en grado suficiente al justiciable el respeto de sus derechos procesales, tales como el derecho a ser oído y el principio de contradicción». Asimismo, también destacó lo señalado en los párrs. 61 a 68, cuyos pasajes más relevantes fueron los siguientes:

61. Así pues, incumbe a la autoridad nacional competente aportar, con arreglo a las normas nacionales de Derecho procesal, la prueba de que la seguridad del Estado se vería efectivamente comprometida en caso de que se comunicaran al interesado, con precisión y por extenso, las razones que constituyan el fundamento de una resolución adoptada en virtud del artículo 27 de la Directiva 2004/38, así como los correspondientes elementos de prueba $[\ldots]$.

63. Si el juez nacional competente llega a la conclusión de que la seguridad del Estado no se opone a que se comuniquen al interesado, con precisión y por extenso, las razones en las que se fundamenta una resolución de prohibición de entrada adoptada en virtud del artículo 27 de la Directiva 2004/38, confiere a la autoridad nacional competente la posibilidad de comunicar al interesado los motivos y las pruebas que falten. Si dicha autoridad nacional no autoriza a que se comuniquen esos motivos y pruebas, el juez procederá al examen de la legalidad de tal decisión basándose exclusivamente en los motivos y pruebas que se hayan comunicado.

64. En cambio, si resulta que la seguridad del Estado se opone efectivamente a que se comuniquen al interesado tales razones, el control judicial de la legalidad de una resolución adoptada en virtud del artículo 27 de la Directiva 2004/38, tal como está previsto en el artículo 31, apartado 1, de la misma, deberá efectuarse, habida cuenta de lo que se ha afirmado en los apartados 51, 52 y 58 de la presente sentencia, en el marco de un procedimiento en el que se ponderen adecuadamente las exigencias derivadas de la seguridad del Estado y las consustanciales al derecho a la tutela judicial efectiva, limitando al mismo tiempo a lo estrictamente necesario las eventuales injerencias en el ejercicio de este último derecho.

65. [...] el procedimiento en cuestión deberá garantizar la observancia del principio de contradicción en la medida más amplia posible [...]. En cualquier caso, reviste especial importancia que se comuniquen al interesado las razones esenciales en las que se fundamenta una resolución de prohibición de entrada [...], ya que la necesaria protección de la seguridad del Estado no puede tener como efecto privar al interesado de su derecho a ser oído ni, por tanto, hacer inefectivo el derecho de éste a interponer los oportunos recursos, tal como está previsto en el artículo 31 de esa misma Directiva.

67. En este contexto, incumbe al juez nacional competente determinar si - y, en su caso, en qué medida - las restricciones a los derechos de defensa del demandante derivadas, en particular, del hecho de no comunicarle, con precisión y por extenso, 
las razones en las que se fundamenta una resolución adoptada en virtud del artículo 27 de la Directiva 2004/38, ni tampoco las pruebas correspondientes, pueden influir en la eficacia probatoria de los elementos de prueba confidenciales.

68. En tales circunstancias, incumbe al juez nacional competente, por una parte, velar por que las razones esenciales que constituyan el fundamento de la resolución de que se trate se comuniquen al interesado de una manera en que se tenga debidamente en cuenta la necesaria confidencialidad de las pruebas y, por otra parte, deducir qué consecuencias puede tener, en virtud del Derecho nacional, el eventual incumplimiento de la referida obligación de comunicación.

Por otro lado, el Tribunal también hizo referencia a la sentencia recaída en el caso Comisión y otros/Kadi ${ }^{49}$, en la cual el TJUE realizó un ejercicio de balance similar entre los requisitos que derivan del derecho a la protección judicial efectiva y aquellos dimanantes de la seguridad de la Unión Europea y sus Estados miembros.

Finalmente, el Tribunal concluyó que, a la vista del procedimiento seguido contra el demandante, la naturaleza de la disputa y el margen de apreciación que ostentaba el Estado checo, las restricciones impuestas al demandante garantizaron el equilibrio entre las partes de tal manera que no se produjo una violación del derecho a un juicio justo del demandante ${ }^{50}$.

Por último, destacaremos la sentencia recaída en el caso Lopes de Sousa Fernandes c. Portuga ${ }^{1}$, la cual también ha sido objeto de análisis en el apartado II.1. Baste recordar que dicho caso versó sobre la responsabilidad de un Estado en relación con la muerte de un paciente en un hospital público.

Para llegar a tal conclusión, la Gran Sala del TEDH hizo uso de varios instrumentos de derecho internacional, tales como el Pacto Internacional de Derechos Económicos, Sociales y Culturales y su observación general núm. 14, relativa al derecho al disfrute del más alto nivel posible de salud ${ }^{52}$. Tras hacer referencia a varios instrumentos regionales del Consejo de Europa, tales como la Carta Social Europea y el Convenio de Oviedo sobre Derechos Humanos y Biomedicina, así como al sistema Interamericano de Derechos Humanos, el Tribunal centró su análisis de derecho comparado en la Carta de los Derechos Fundamentales de la Unión Europea.

49 Sentencia del Tribunal de Justicia (Gran Sala) de 18 de julio de 2013, Comisión y otros/Kadi, C-584/10 P, EU:C:2013:518.

50 Regner v. the Czech Republic [GC], supra nota 46, párr. 161.

51 Lopes de Sousa Fernandes v. Portugal [GC], supra nota 2.

52 Observación general núm.14, E/C.12/2000/4, 11 de agosto de 2000. 
A continuación el Tribunal mencionó la Recomendación del Consejo sobre la seguridad de los pacientes, en particular la prevención y lucha contra las infecciones relacionadas con la asistencia sanitaria ${ }^{53}$, la cual solicitaba a los Estados miembros, inter alia, revisar y actualizar «con regularidad las normas de seguridad o las mejores prácticas aplicables a la atención sanitaria prestada en su territorio», «aplicar las medidas de prevención y lucha a escala nacional o regional para favorecer la contención de las infecciones relacionadas con la asistencia sanitaria», "facilitar directrices y recomendaciones a escala nacional» e informar a los pacientes sobre «los procedimientos de denuncia, las soluciones posibles y los procedimientos de recurso, así como las condiciones aplicables».

Todo lo anterior sirvió de fundamento para que el Tribunal concluyera que, en el presente caso, el marido de la demandante podría haber muerto a causa de una negligencia médica y, por tanto, el Estado no había cumplido con la obligación de respetar las obligaciones que dimanan de la vertiente procesal del art. 2 del Convenio.

\section{ESPAÑA Y EL TRIBUNAL EUROPEO DE DERECHOS HUMANOS}

A continuación realizaremos un somero repaso de las sentencias y decisiones más relevantes publicadas en este último cuatrimestre de 2017.

En este apartado es menester destacar la importante sentencia recaída en el caso N.D. y N.T. c. España ${ }^{54}$. El presente caso tiene una relevancia destacable, toda vez que es la primera vez que el Tribunal se pronuncia sobre la práctica de «expulsiones en caliente» realizadas por España en la frontera de Melilla. No obstante, cabe una precisión: la sentencia fue recurrida por el Gobierno y el pasado 29 de enero de 2018 un colegio de cinco jueces aceptó el reenvío ante la Gran Sala, todo ello de conformidad con el art. 43 del Convenio.

Los demandantes son de nacionalidad maliense y marfileña, respectivamente. El día 13 de agosto los demandantes salieron del campamento del Monte Gurugú y trataron de entrar en España junto con un grupo de subsaharianos a través del puesto fronterizo de Melilla. Este puesto fronterizo se caracteriza por disponer de tres vallas consecutivas, las dos exteriores de 6 metros de altura y la interior de 3 metros de altura. En concreto, los de-

53 Recomendación del Consejo, de 9 de junio de 2009, sobre la seguridad de los pacientes, en particular la prevención y lucha contra las infecciones relacionadas con la asistencia sanitaria (2009/C 151/01), DO L 151, de 3 de julio de 2009, págs. 1 y ss.

54 N.D. and N.T. v. Spain, nos. 8675/15 y 8697/15. 
mandantes, junto con otros inmigrantes, treparon por la primera valla por la mañana con el objetivo de cruzar la frontera y acceder a suelo español. Tras más de 14 horas intentando saltar las vallas consiguieron finalmente acceder a la tercera valla. En ese momento fueron bajados de la misma con ayuda de las fuerzas de seguridad españolas. Los demandantes fueron detenidos junto con otros inmigrantes por miembros de la Guardia Civil, quienes les esposaron y devolvieron a Marruecos.

Los demandantes no fueron en ningún momento objeto de procedimiento de identificación alguno. Tampoco tuvieron la posibilidad de exponer sus circunstancias personales ni de ser asistidos por abogados, intérpretes o médicos. Fueron conducidos a continuación, junto con otras personas que habían sido también rechazadas en circunstancias similares, a Fez, donde fueron abandonados. Los demandantes afirman que entre 75 y 80 inmigrantes subsaharianos fueron también enviados a Marruecos ese mismo 13 de agosto de 2014.

Según el Gobierno, los hechos del presente caso se habrían producido fuera de la jurisdicción del Estado demandado toda vez que, según este, los demandantes nunca llegaron a entrar en territorio español. El TEDH consideró este último hecho irrelevante, afirmando que no era necesario establecer si la valla fronteriza levantada entre Marruecos y España se situaba o no en territorio de este último Estado y recordó que desde el momento en que hubiera un «control de jure» ejercido por el Estado en cuestión sobre los individuos afectados, se entiende que el Tribunal tiene jurisdicción sobre los hechos ${ }^{55}$, ya se encuentren estas personas en el interior del territorio del Estado o en al borde de sus fronteras terrestres.

Así, en opinión del TEDH, desde el momento en que los demandantes descendieron de las vallas fronterizas estos se encontraron bajo el control continuo y exclusivo, al menos, de facto, de las autoridades españolas. En consecuencia, el TEDH determinó claramente que no existía "ninguna duda» de que los hechos que sustentan las alegadas violaciones estaban bajo la «jurisdicción» de España de conformidad a lo estipulado en el art. 1 del Convenio ${ }^{56}$.

En cuanto al fondo de la demanda, el TEDH recordó que se debe entender por «expulsión colectiva» toda medida que "compele a unos extranjeros, en tanto que grupo, a abandonar un país, salvo en los casos en que tal medida se toma con base en un examen razonable y objetivo de las circunstancias particulares de cada uno de los extranjeros que forman parte del grupo ${ }^{57}$.

55 Ibid., párr. 54. Véase también, Hirsi Jamaa and others v. Itahly, 27765/09, párr. 77.

56 N.D. and N.T. v. Spain, supra nota 55, párr. 55.

57 Ibid., párr. 98. 
El TEDH señaló además que el fin del art. 4 del Protocolo 4 era el de evitar que los Estados pudieran expulsar a un determinado número de extranjeros sin examinar sus circunstancias personales y, por tanto, sin permitirles exponer sus argumentos que se oponen a la medida adoptada por la autoridad competente ${ }^{58}$. Dicho lo anterior, el Tribunal recaló que en ningún momento los demandantes fueron objeto de procedimiento alguno. En estas circunstancias, el TEDH estimó que el procedimiento seguido no permitió de ningún modo dudar del carácter colectivo de las expulsiones criticadas ${ }^{59}$. Por lo anterior, el TEDH declaró que el Estado español había violado el art. 4 del Protocolo 4.

En lo que respecta al art. 13 en relación con el ya mencionado art. 4 del Protocolo 4, cabe señalar que los demandantes se quejaron de la ausencia de un recurso efectivo que les permitiera impugnar su expulsión desde la perspectiva del carácter «colectivo». El Tribunal constató que, en el presente caso, la cuestión del carácter suspensivo de pleno derecho del recurso ni siquiera se podía analizar, ya que los demandantes ni siquiera habían tenido acceso, antes de su expulsión a Marruecos, a ningún procedimiento tendente a su identificación y a la comprobación de sus circunstancias personales ${ }^{60}$. Cabe además señalar que el TEDH concedió un valor particular a la versión de los demandantes, toda vez que esta estaba corroborada por numerosos testimonios recogidos, entre otros, por ACNUR o por el comisario $\mathrm{DDHH}^{61}$.

Habida cuenta de las circunstancias del presente caso y el carácter inmediato de la expulsión, el Tribunal estimó que a los demandantes se les había privado de toda vía de recurso que les hubiera permitido presentar ante una autoridad competente su queja respecto del art. 4 del Protocolo 4 y obtener un control atento y riguroso de su solicitud antes de su devolución, por lo que el TEDH estimó que se había producido una vulneración del art. 13 del Convenio en relación con el art. 4 du Protocolo 4 del Convenio ${ }^{62}$.

Por otro lado, en el caso López Elorza c. España, el TEDH analizó y desarrolló su jurisprudencia relativa a la compatibilidad del art. 3 del Convenio de una extradición a Estados Unidos en la que el demandante se enfrentaba a la posibilidad de ser condenado a cadena perpetua.

Cabe señalar que en el presente caso, con fecha 2 de julio de 2015, el demandante solicitó ante el TEDH la adopción de una medida cautelar: la

\footnotetext{
58 Ibid., párr. 99.

59 Ibid., párr. 107.

60 Ibid., párr. 108.

61 Ibid., párr. 109.

62 Ibid. párrs. 121 y 122.
} 
paralización de su inminente extradición a Estados Unidos. El argumento principal fue que el demandante había sido acusado de "conspiración para distribuir heroína" y "conspiración para importar heroína» y que ambos delitos podían acarrear la cadena perpetua, la cual, por la forma en la que se impone en Estados Unidos, era contraria al art. 3 del Convenio.

Ese mismo 2 de julio de 2015 el Tribunal decidió aplicar temporalmente la medida cautelar y hacer dos preguntas al Gobierno en relación con la pena a la que podía ser condenado el demandante y los concretos mecanismos en el sistema estadounidense para poder revisar una condena a cadena perpetua. El 23 de julio de 2015 el Gobierno remitió una respuesta junto con un informe elaborado por la Oficina de Asuntos Internacionales del Departamento de Justicia de Estados Unidos. En vista de la respuesta recibida, el TEDH decidió mantener la medida cautelar hasta que pudiera analizar con profundidad el presente caso y emitir la oportuna sentencia.

En primer lugar, el Tribunal recordó su jurisprudencia relativa a la compatibilidad de la cadena perpetua con el art. 3 del Convenio al señalar que la misma no está prohibida por el señalado artículo, siempre y cuando la misma no sea "extremadamente [grossly] desproporcionada» ${ }^{63}$.

El Tribunal también recordó que, sin perjuicio de lo anterior, la condena a cadena perpetua estaba sujeta a unos límites. En el caso Vinter y otros c. Reino Unido el Tribunal determinó que, a la luz del fin de prevención y rehabilitación de una pena, una condena a cadena perpetua debía tener la posibilidad de ser revisada de tal manera que permitiera a las autoridades nacionales considerar si existen cambios en la vida del prisionero de tal calibre (encaminados a la rehabilitación) que hacían que la detención del prisionero ya no estuviera justificada ${ }^{64}$. En dicha sentencia el Tribunal estableció expresamente que todo condenado a cadena perpetua tiene derecho a saber, al principio de su condena, qué es lo que puede hacer y cuáles son los requisitos para su puesta en libertad en un futuro ${ }^{65}$.

Más tarde, en el caso Trabelsi c. Bélgica ${ }^{66}$, el TEDH consideró que el mecanismo de revisión de una condena a cadena perpetua requería que las autoridades nacionales analizaran la solicitud sobre la base de unos «criterios objetivos y pre-establecidos» ${ }^{67}$.

63 Vinter and others $v$. the United Kingdom [GC], nos. 66069/09, 130/10 and 3896/10, párr. 88.

64 Ibid., párr. 119.

65 Ibid., párr. 122.

66 Trabelsi v. Belgium, no. 140/10.

67 Ibid., párr 137. 
En el presente caso el Tribunal centró su análisis en la existencia o no de un riesgo a que el demandante fuera objeto de un tratamiento contrario al art. 3 del Convenio. Para ello, tuvo en cuenta varios factores relevantes. En primer lugar, el Tribunal observó que en Estados Unidos existían unas "pautas para determinar una condena» (sentencing guidelines) que, en el caso del demandante, recomendaban que la condena oscilara entre 15 y 19 años y 7 meses, lo cual era sin duda una condena inferior a la cadena perpetua ${ }^{68}$. Si bien el TEDH destacó que dichas pautas eran meramente indicativas y que los jueces gozaban de discreción a la hora de imponer una condena, lo cierto es que el demandante no había expuesto ninguna razón que defendiera la posibilidad de no respetar dichas pautas. Asimismo, en el improbable caso de que las mismas no fueran respetadas, el TEDH observó que el demandante disponía de un recurso especial para defender la incorrecta aplicación de los rangos establecidos en la guía ${ }^{69}$.

Por otro lado, el TEDH destacó que, a diferencia del caso Trabelsi (donde además las citadas pautas de condena ya proponían la condena a cadena perpetua para los delitos que se le imputaban al señor Trabelsi), en el presente caso los coautores de los delitos de los que se acusaba al señor Elorza ya habían sido procesados y condenados a unas penas de 72,14 y 12 meses, respectivamente, y ello a pesar de que se les aplicaba el mismo rango de penas al que ahora se enfrentaba el demandante (esto es, entre 15 y 19 años y 7 meses) ${ }^{70}$.

El Tribunal destacó que, si bien existían muchos factores que contribuían a la hora de determinar una eventual pena y que era imposible analizar todas las combinaciones concebibles, el demandante tenía la obligación de presentar prueba suficiente que acreditara que existían «razones de peso» (substantial grounds) para considerar que el demandante iba a ser condenado a cadena perpetua y ser sujeto a un tratamiento contrario al art. 3 del Convenio ${ }^{71}$. Por todo lo anterior, el TEDH declaró que no se produjo una violación del citado precepto.

Por último, también se debe destacar el caso Jiménez Ruiz c. España ${ }^{72}$ toda vez que es uno de los pocos casos donde el Gobierno ha llegado a un acuerdo amistoso con un demandante.

La demandante reclamó que la negativa de reconocerle una pensión de viudedad con base en la falta de notificación al juez de la reconciliación con su

\footnotetext{
López Elorza v. Spain, supra, párr. 112.

Ibid., párr.. 113.

Ibid., párr. 115.

Ibid., párr. 118.

Jiménez Ruiz v. Spain, no. 2649/16.
} 
exmarido, tras haberse separado judicialmente, podía atentar contra el principio de no discriminación reconocido en el art. 14 del Convenio, junto al derecho a la propiedad garantizado por el art. 1 del Protocolo 1.

Los días 25 de mayo y 9 de junio de 2017, el Tribunal recibió una propuesta de acuerdo amistoso firmada por las partes. Con base en dicha propuesta, el Gobierno se comprometió a:

- Reconocer la vulneración del art. 14 del Convenio en conjunción con el art. 1 del Protocolo 1.

- Acordar una pensión de jubilación para la demandante como consecuencia del fallecimiento de su pareja por un importe mensual de 1662,96 euros.

- Abonar a la demandante los atrasos de la pensión correspondiente al período comprendido entre el 5 de octubre de 2010 y el 5 de mayo de 2017 es decir, 135 130,68 euros.

- Abonar 19188 euros a la demandante en concepto de indemnización.

- Abonar 6000 euros en concepto de costas.

Por su parte, la demandante renunció a cualquier otra pretensión contra España como consecuencia de los hechos que dieron lugar a la demanda. En esta ocasión, y de conformidad con lo preceptuado en el art. 39 del Convenio, el Tribunal tomó nota del acuerdo amistoso al que llegaron las partes, estimó que dicho acuerdo se inspiraba en «el respeto de los derechos humanos reconocidos en el Convenio y sus protocolos» y manifestó que no apreciaba la existencia de motivo alguno para continuar con el examen de la demanda. Por todo lo anterior, el Tribunal decidió archivar el caso. 